\title{
No Haploinsufficiency but Loss of Heterozygosity for EXT in Multiple Osteochondromas
}

\author{
Christianne M.A. Reijnders, ${ }^{*}$ \\ Cathelijn J.F. Waaijer, ${ }^{*}$ Andrew Hamilton, ${ }^{\dagger}$ \\ Emilie P. Buddingh, ${ }^{\ddagger}$ Sander P.D. Dijkstra, ${ }^{\S}$

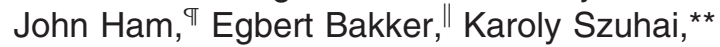 \\ Marcel Karperien, ${ }^{\dagger \dagger}$ Pancras C.W. Hogendoorn, ${ }^{*}$ \\ Sally E. Stringer, ${ }^{\dagger}$ and Judith V.M.G. Bovée* \\ From the Departments of Pathology, ${ }^{*}$ Pediatrics, ${ }^{*}$ Orthopedic \\ Surgery, ${ }^{\circledR}$ Human and Clinical Genetics," and Molecular Cell \\ Biology,** Leiden University Medical Center, Leiden, The \\ Netherlands; the Section of Cardiovascular Medicine, School of \\ Biomedicine, Faculty of Medical and Human Sciences, ${ }^{\dagger}$ \\ Manchester Academic Health Science Centre (CMFT), University \\ of Manchester, Manchester, United Kingdom; the Department of \\ Orthopedics, "Inze Lieve Vrouwe Gasthuis (OLVG), Amsterdam, \\ The Netherlands; and the MIRA Institute for Biomedical \\ Technology and Technical Medicine, ${ }^{\text {t† }}$ Department of Tissue \\ Regeneration, University of Twente, Enschede, The Netherlands
}

Multiple osteochondromas (MO) is an autosomal dominant disorder caused by germline mutations in EXT1 and/or EXT2. In contrast, solitary osteochondroma (SO) is nonhereditary. Products of the EXT gene are involved in heparan sulfate (HS) biosynthesis. In this study, we investigated whether osteochondromas arise via either loss of heterozygosity ( 2 hits) or haploinsufficiency. An in vitro three-dimensional chondrogenic pellet model was used to compare heterozygous bone marrow-derived mesenchymal stem cells (MSCs $E X T^{w t /-}$ ) of MO patients with normal MSCs and the corresponding tumor specimens (presumed $E X T^{-/}$). We demonstrated a second hit in EXT in five of eight osteochondromas. HS chain length and structure, in vitro chondrogenesis, and EXT expression levels were identical in both $\boldsymbol{E X T ^ { w t / - }}$ and normal MSCs. Immunohistochemistry for HS, HS proteoglycans, and HS-dependent signaling pathways (eg, TGF- $\beta / B M P$, Wnt, and PTHLH) also showed no differences. The cartilaginous cap of osteochondroma contained a mixture of HS-positive and HS-negative cells. Because a heterozygous EXT mutation does not affect chondrogenesis, EXT, HS, or downstream signaling pathways in MSCs, our results refute the haploinsufficiency theory. We found a second hit in $63 \%$ of analyzed osteochondromas, support- ing the hypothesis that osteochondromas arise via loss of heterozygosity. The detection of the second hit may depend on the ratio of HS-positive (normal) versus HSnegative (mutated) cells in the cartilaginous cap of the osteochondroma. (Am J Pathol 2010, 177:1946-1957; DOI: 10.2353/ajpath.2010.100296)

Osteochondromas (OCs) are benign cartilage forming tumors, which are present at the surface of the long bones. ${ }^{1}$ OCs manifest and increase in size the first decade of life. The growth of OCs ceases during puberty when the growth plate closes. Multiple osteochondromas (MO), previously known as hereditary multiple exostoses, is an autosomal dominant disorder, caused by mutations in the tumor suppressor genes EXT1 or EXT2.2,3 The main complication is transformation toward malignancy, which occurs in 0.5 to $5 \%$ of the patients. ${ }^{2-4}$

According to Knudson's two-hit model for tumor suppressor genes, ${ }^{5}$ both alleles should be inactivated for OC formation in $\mathrm{MO}$ and solitary osteochondroma (SO) patients. Loss of heterozygosity of EXT1 and/or EXT2 was shown in solitary OCs, ${ }^{6-8}$ in hereditary OCs, ${ }^{7}$ and in secondary peripheral CS, ${ }^{7,9-11}$ supporting the two-hit model. However, in a considerable proportion of the $\mathrm{MO}$ patients loss of the remaining wild-type allele has not been detected, ${ }^{12-14}$ resulting in a longstanding discussion in the literature as to whether OCs in $\mathrm{MO}$ patients could arise through haploinsufficiency.

The EXT gene products catalyze heparan sulfate (HS) biosynthesis in the Golgi apparatus by elongation of the HS chains. ${ }^{15-18}$ EXT and HS proteoglycans (HSPGs) are essential for the diffusion of the morphogens Hedgehog

Supported by Netherlands Organization for Scientific Research (917-76315 to C.M.A.R. and J.V.M.G.B.) and British Heart Foundation (FS/05/060 to S.E.S.). This study was performed within the context of the EuroBoNeT consortium (018814), a European Commission granted Network of Excellence for studying the pathology and genetics of bone tumors.

Accepted for publication June 7, 2010

Supplemental material for this article can be found on http://ajp. amjpathol.org.

Address reprint requests to Judith V. M. G. Bovée, M.D., Ph.D., Department of Pathology, Leiden University Medical Center, PO Box 9600, L1-Q, 2300 RC Leiden, The Netherlands. E-mail: j.v.m.g.bovee@lumc.nl. 
$(H \mathrm{~h})$, decapentaplegic (dpp, human homologues transforming growth factor [TGF]- $\beta$ and bone morphogenic protein $[\mathrm{BMP}]$ ) and wingless (wg, human homologue wnt). ${ }^{19-22}$ These downstream pathways of EXT play an important role in development and in endochondral bone formation. During normal growth, Indian hedgehog $(\mathrm{IHh})$ and parathyroid hormone-like hormone (PTHLH) regulate proliferation and differentiation of chondrocytes of the growth plate. In OCs the function of the EXT genes is impaired. This might lead to accumulation of HSPGs in the Golgi apparatus and cytoplasm of the OC chondrocytes, ${ }^{23}$ which is followed by disturbed downstream pathways of EXT. We and others previously showed that the $\mathrm{IHh}$ pathway is active in OCs, ${ }^{24,25}$ while the PTHLH signaling, regulating chondrocyte proliferation, is absent in OCs and up-regulated on malignant transformation. ${ }^{26,27}$ Wnt signaling and TGF- $\beta$ signaling are also active in the majority of the OCs. ${ }^{25}$

In this study our aim was to investigate whether OCs arise via the classical two-hit model for tumor suppressor genes or via haploinsufficiency (gene dosage model, ie, the loss of one EXT allele). So, we first determined whether the second hit was present in the cartilage cap of $\mathrm{MO}$ and SO patients. Subsequently, we used an in vitro $3 \mathrm{D}$ chondrogenic pellet model in which bone marrowderived mesenchymal stem cells (MSCs) of healthy donors and SO patients (EXTwtiwt) were compared with MSCs of MO patients $\left(E X T^{w t /-}\right)$ and tissue from the car-

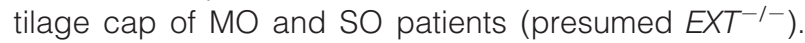
MSCs 3D in vitro pellets provide a suitable model to study chondrogenesis. We investigated EXT expression, HS structure and chain length, and RNA and protein expression of members of the EXT downstream pathways in the different EXT conditions.

\section{Materials and Methods}

\section{Patient Material}

Different specimens of resected OC cartilage cap of MO patients $(n=8)$ and SO patients $(n=3)$ were collected: ie, fresh frozen material, formalin-fixed paraffin-embedded material (after decalcification by either EDTA or formic acid), and tissue processed for cell culturing. From the same patients as well as from healthy donors $(n=3)$ MSCs were isolated from bone marrow $(0.5-5 \mathrm{ml})$. Samples were obtained during surgery at two different hospitals (Leiden University Medical Center [LUMC] and Onze Lieve Vrouwe Gasthuis [OLVG]). Additionally, blood samples of $\mathrm{MO}$ patients were collected to isolate lymphocyte DNA, and EXT1 and EXT2 mutation analysis was performed as described. ${ }^{28,29}$ Patient characteristics are summarized in Table 1. All specimens were obtained after informed consent and approval of the Ethical Medical Committee (P07.078) of the LUMC and OLVG. Postnatal growth plate samples had previously been collected from resections or biopsies for orthopedic clinical conditions not related to osteochondroma or chondrosarcoma. ${ }^{23}$ All samples were handled according to the eth- ical guidelines as described in the Code for Proper Secondary Use of Human Tissue in The Netherlands of the Dutch Federation of Medical Scientific Societies.

\section{EXT Mutation Analysis and DNA Tiling Array}

Normal lymphocyte DNA of MO patients and DNA isolated from the dissected cartilaginous caps of the OCs were sequenced and compared. ${ }^{28}$ The SO specimens were hybridized on a custom made oligonucleotide array. ${ }^{30}$ Tumor percentage was $>70 \%$ except for L2467 $(<50 \%)$. The number of genes spotted on the array has been extended to 144 genes selected for their function in cartilage biosynthesis (Supplemental Table 1, available at $h$ ttp://ajp.amjpathol.org). Sequence data and DNA tiling array data were analyzed with Mutation Surveyor (Soft Genetics, LCC, version 3.24, State College, PA) and Nexus (BioDiscovery Inc., version 3.6, El Segundo, CA), respectively

\section{Cell Culture}

\section{Monolayer Culture}

MSCs were expanded in low-glucose (1 g/L) DMEM (Invitrogen, Breda, NL) supplemented with 10\% fetal bovine serum (HyClone, Thermo Scientific, Etten-Leur, NL) and $2 \% \mathrm{P} / \mathrm{S}$. Cartilage cap cells were isolated from SO and MO patients and expanded in RPMI (Invitrogen) supplemented with 10\% fetal bovine serum (Invitrogen) and $2 \% \mathrm{P} / \mathrm{S}$ (Invitrogen). Cells were kept at $37^{\circ} \mathrm{C}$ and $5 \%$ $\mathrm{CO}_{2}$. Medium was changed twice a week.

\section{Flow Cytometric Analysis MSCs}

Flow cytometric analysis was performed for all MSC samples at passage 3 to 6 to confirm that adherent cells expanded from the bone marrow were MSCs. Monoclonal antibodies used were anti-CD86-FITC (1:40), antiHLA-DR FITC (1:30), anti-CD31-PE (1:200), anti-CD34-PE (1:120), anti-CD73-PE (1:25), anti-CD90-PE (1:500), antiCD3-PerCPCY5.5 (1:10), and anti-CD45-PerCPCY5.5 (1: 200; all Becton Dickinson, Franklin Lakes, NJ), and antiCD105-PE (1:40; Ancell, Bayport, MN). Cells were harvested using trypsin/EDTA (Invitrogen) and washed with $0.5 \%$ BSA/PBS and incubated with the respective antibodies for 20 minutes at $4^{\circ} \mathrm{C}$. Flow cytometry was performed using a FACS Calibur System (Becton Dickinson) and results were analyzed using CellQuest Pro Software (Becton Dickinson).

\section{Adipogenic and Osteogenic Differentiation}

To establish the multipotent differentiation capacity of the MSCs (adipogenic and osteogenic) a subset of MSCs ( $n=$ 4) was tested in duplicate. Cells were seeded at a density of 15,000 cells per $\mathrm{cm}^{2}$ in $0.1 \%$ gelatin coated plates and cultured in $\alpha$-MEM (Lonza, Breda, NL) with 10\% FCS, $1 \%$ Glutamax (Invitrogen), 1\% P/S, dexamethasone $\left(10^{-7}\right.$ 
Table 1. Patient Characteristics with EXT Mutations and EXT Levels

\begin{tabular}{|c|c|c|c|c|c|c|c|c|c|c|}
\hline ID & $\mathrm{M}, \mathrm{F}$ & Age & $\begin{array}{l}\mathrm{N}, \mathrm{SO} \\
\mathrm{MO}\end{array}$ & $\begin{array}{l}\text { OC, } \\
\text { PCS }\end{array}$ & Location & Germline & Tumor & EXT1* & EXT2* $^{*}$ & $\begin{array}{c}\mathrm{HS} \\
(10 \mathrm{E} 4)^{\dagger}\end{array}$ \\
\hline L2069 & M & 11 & $\mathrm{MO}$ & OC & $\begin{array}{l}\text { Tibia; } \\
\text { femur }\end{array}$ & $\begin{array}{l}\text { EXT1, exon 1 } \\
\text { c.538_539delAG, } \\
\text { p.Ser180fsX7 }\end{array}$ & Heterozygous & 0.36 & 1.17 & $\mathrm{Nd}$ \\
\hline L2227 & F & 13 & $\mathrm{MO}$ & OC & $\begin{array}{l}\text { Tibia; } \\
\text { femur }\end{array}$ & $\begin{array}{l}\text { EXT1, exon } 1 \text { c. } 364 C>T, \\
\text { p.Gln122X and } \\
\text { c.373G }>\text { T, p.Glu125X }\end{array}$ & Homozygous & 0.17 & 0.91 & $\sim 50 \%$ \\
\hline L2232 & M & 39 & $\mathrm{MO}$ & OC & Femur & $\begin{array}{l}\text { EXT1, exon } 8 \text { c.1696G }>T \text {, } \\
\text { p.Glu566X }\end{array}$ & $\mathrm{Nd}$ & $\mathrm{Nd}$ & $\mathrm{Nd}$ & $\sim 60 \%$ \\
\hline L2254 & $\mathrm{M}$ & 43 & $\mathrm{MO}$ & PCSI & Os pubis & $\begin{array}{l}\text { EXT2, exon } 6 \text { c.980delG, } \\
\text { p.Gly327AlafsX5 }\end{array}$ & Homozygous & 0.42 & $\mathrm{BDL}$ & $\sim 20 \%$ \\
\hline L2467 & $F$ & 8 & $\mathrm{MO}$ & OC & Femur & $\begin{array}{l}\text { EXT1, exon } 1 \\
\text { c.643_662del, } \\
\text { p.Met215GInfsX }\end{array}$ & Heterozygous & 0.27 & 1.70 & $\sim 50 \%$ \\
\hline L2240 & M & 45 & $\mathrm{MO}$ & OC & Hip & $\begin{array}{l}\text { Mutation analysis: } \\
\text { negative; DNA tiling } \\
\text { array: } 80.7 \mathrm{~kb} \text { deletion } \\
\text { intron EXT1, } 68.9 \mathrm{~kb} \\
\text { amplification upstream }\end{array}$ & $\mathrm{Nd}$ & $\mathrm{Nd}$ & $\mathrm{Nd}$ & Negative \\
\hline L2352 & F & 10 & $\mathrm{MO}$ & $\mathrm{OC}$ & Femur & $\begin{array}{l}\text { EXT1, del exon 4-11; } \\
\text { EXT2, UV ex10 } \\
\text { c.1641C>T, } \\
\text { p.Asp547Asp }\end{array}$ & Homozygous & 0.43 & 1.54 & $\sim 40 \%$ \\
\hline L2378 & F & 17 & $\mathrm{MO}$ & OC & Humerus & $\begin{array}{l}\text { Mutation analysis: } \\
\text { negative; DNA tiling } \\
\text { array: none in EXT1/2 }\end{array}$ & $\mathrm{Nd}$ & 0.20 & 0.26 & $\sim 25 \%$ \\
\hline L2084 & M & 18 & SO & OC & Tibia & $\mathrm{Nd}$ & $\begin{array}{l}\text { Homozygous loss } \\
\text { EXT1; partly } \\
\text { hemizygous }\end{array}$ & 0.33 & 0.66 & $\sim 15 \%$ \\
\hline L2361 & M & 37 & SO & PCSI & Femur & $\mathrm{Nd}$ & $\begin{array}{l}\text { Hemizygous loss } \\
\text { EXT1 }\end{array}$ & 0.32 & 1.12 & $\sim 10 \%$ \\
\hline L2370 & M & 9 & SO & $\mathrm{OC}$ & Tibia & $\mathrm{Nd}$ & $\begin{array}{l}\text { Homozygous loss } \\
\text { EXT1; partly } \\
\text { hemizygous; } \\
\text { homozygous } \\
\text { deletion } 6 \mathrm{p} \\
\text { (CNV region) }\end{array}$ & $\mathrm{Nd}$ & $\mathrm{Nd}$ & $\sim 10 \%$ \\
\hline N1 & M & 15 & $\mathrm{~N}$ & & & $\mathrm{Nd}$ & - & - & - & - \\
\hline N3 & M & 50 & $\mathrm{~N}$ & & & $\mathrm{Nd}$ & - & - & - & - \\
\hline N4 & $\mathrm{F}$ & 27 & $\mathrm{~N}$ & & & $\mathrm{Nd}$ & - & - & - & - \\
\hline
\end{tabular}

M indicates male; F, female; N, healthy donor; MO, multiple osteochondromas; SO, solitary osteochondroma; OC, osteochondroma; PCSI peripheral chondrosarcoma grade I; CNV, copy number variation.

${ }^{*}$ Relative EXT1 or EXT2 mRNA expression of OC as a fraction of the average growth plate expression.

tPercentage HS chain (10E4)-positive cells present in cartilage cap; BDL, below detection level; Nd, not determined; N1, N3, N4, healthy donors, no tumor material available.

mol/L; Sigma-Aldrich, Zwijndrecht, NL) and ascorbate-2phosphate (50 $\mu \mathrm{g} / \mathrm{ml}$; Sigma-Aldrich). Adipogenic medium was supplemented with insulin (100 $\mu \mathrm{g} / \mathrm{ml}$; Sigma-Aldrich), indomethacin (0.5 mmol/L; Sigma-Aldrich) and 1-methyl-3isobutylxantine (IBMX; $50 \mu \mathrm{mol} / \mathrm{L} ;$ Sigma-Aldrich). Osteogenic medium was supplemented with $5 \mathrm{mmol} / \mathrm{L} \beta$-glycerolphosphate, which was added to the medium after 7 days of culture. Medium was changed twice a week. After 3 weeks of culture, cells were fixed 10 minutes with $4 \%$ paraformaldehyde and stained for 10 minutes with oil red $\mathrm{O}(3$ $\mathrm{mg} / \mathrm{ml})$ or 5 minutes with Alizarin red $(20 \mathrm{mg} / \mathrm{ml}$ ) to assess adipogenic and osteogenic differentiation, respectively.

\section{Chondrogenic Differentiation}

At $90 \%$ confluence, the MSCs or cartilage cap cells were washed, harvested, and pellets were made. Chondrogenic medium consisted of high-glucose $(4.5 \mathrm{~g} / \mathrm{L})$
DMEM (Invitrogen), proline (40 $\mu \mathrm{g} / \mathrm{ml}$; Sigma-Aldrich), ITS premix (insulin, human transferrin and selenous acid; 50 $\mathrm{mg} / \mathrm{ml}$; Becton Dickinson), sodium pyruvate (100 $\mu \mathrm{g} / \mathrm{ml}$; Sigma-Aldrich), Glutamax (1\%) and P/S (final concentration: $100 \mathrm{U} / \mathrm{ml}$ ) supplemented with ascorbate-2-phosphate (50 $\mu \mathrm{g} / \mathrm{ml}$ ), TGF- $\beta 3$ ( $10 \mathrm{ng} / \mathrm{ml}$; R\&D Systems, Abingdon, UK), dexamethasone $\left(10^{-7} \mathrm{~mol} / \mathrm{L}\right)$ and BMP-6 $(500 \mathrm{ng} / \mathrm{ml}, \mathrm{R} \& \mathrm{D}$ Systems). Cells were seeded at a density of 200,000 cells per U-shaped well in a 96-well plate (50 pellets per time series). Subsequently, plates were centrifuged at $1200 \mathrm{rpm}$ for 7 minutes. Medium was changed twice a week. Pellets were harvested at 2, 4, and 6 weeks.

\section{HS Extraction}

To recover intracellular and extracellular HS, cells and media were removed from culture flasks at $70-80 \%$ confluence by scraping with a sterile cell scraper. Triton- 
X100 (1\%; Sigma-Aldrich) and protease (1 mg/ml; SigmaAldrich) were added to the cell suspensions and incubated for 16 hours at $55^{\circ} \mathrm{C}$. HS extraction was as described by Chen and colleagues. ${ }^{31}$ An additional desalting step using a PD-10 chromatography (GE Healthcare, Little Chalfont, UK) was performed at the end of the protocol to remove residual salts from the sample.

\section{HS Chain Length Analysis}

For HS chain length determination, cells were incubated in growth media containing $10 \mu \mathrm{Ci} / \mathrm{ml}$ glucosamine hydrochloride d-[6-3H(N)] (Perkin Elmer, Waltham, MA) for 24 hours, followed by HS extraction as described above. Further preparation of HS for chain length analysis was performed according to Robinson and colleagues. ${ }^{32} \mathrm{HS}$ chain length was determined by size-exclusion chromatography on a Sepharose CL-6B column (GE Healthcare) using a $10 \mathrm{mmol} / \mathrm{L}$ Tris-base, $0.2 \mathrm{~mol} / \mathrm{L} \mathrm{NaCl}, \mathrm{pH} 7.5$ buffer at a flow rate of $4 \mathrm{ml} /$ hour. Fractions were collected at 1 minute intervals. Fractions were mixed with $3 \mathrm{ml}$ Optiphase Hisafe 2 scintillation fluid (Perkin-Elmer) and radiolabeled HS content was determined by scintillation counting (Packard Tri-Carb 2500TR liquid scintillation analyzer [Canberra, Meriden, CT]). The void and total volumes of column were determined by dextran blue and phenol red, respectively. HS chain length was estimated from calibration data described by Wasteson. ${ }^{33}$

\section{SAX-HPLC for Analysis of HS Chain Composition}

HS digestion for disaccharide analysis was performed according to Chen and colleagues. ${ }^{31}$ Before loading onto HPLC, $5 \mu$ l Milli-Q water was added to the sample. Disaccharide composition was determined by Strong Anion-exchange (SAX) chromatography on a ProPac PA-1 column (Dionex, Sunnyvale, CA) using postcolumn fluorescent detection. Eluents used were as follows: $A$, Milli-Q water $\mathrm{pH}$ 3.5; $\mathrm{B}, 1 \mathrm{~mol} / \mathrm{L} \mathrm{NaCl} \mathrm{pH} \mathrm{3.5;} \mathrm{C,} \mathrm{0.5 \%} \mathrm{2-cyanoacet-}$ amide; D, $0.25 \mathrm{~mol} / \mathrm{L} \mathrm{NaOH}$. Flow rate was $1 \mathrm{ml} / \mathrm{min}$. The gradient program was as follows: 1 minute. eluent $A$, $1-45$ minutes. 0 to $100 \%$ eluent B, $45-55$ minutes. $100 \%$ eluent B, 55-57 minutes. step-wise decrease of eluent B to $0 \%$, followed by a wash in eluent $A$ for 13 minutes. The eluate was mixed with equal proportions of 0.5\% 2-cyanoacetamide (HPLC grade, Fluka, Sigma, Dorset, UK) and $0.25 \mathrm{M} \mathrm{NaOH}$ (HPLC grade, Sigma) that were dispensed at a flow rate of $0.45 \mathrm{ml} / \mathrm{min}$, and reacted at $122^{\circ} \mathrm{C}$ in a post column reactor (CRX400, Pickering Laboratories, Mountain View, CA). The eluate was then cooled in line in a cooling tower maintained at approximately $10^{\circ} \mathrm{C}$ and detected by in-line fluorescence at 346 $\mathrm{nm}$ excitation; $410 \mathrm{~nm}$ emission. An equal mix $(0.16 \mathrm{nmol}$ total) of the HS disaccharides: $\triangle \cup A-G l c N A c, \Delta \cup A$ GlcNS, $\Delta \cup A-G 1 c N A c 6 S, \Delta \cup A-G l c N S 6 S, \Delta \cup A 2 S-G I c N S$, and $\triangle$ UA2S-GIcNS6S (Seikagaku, Tokyo, Japan) was used to calibrate the equipment. Eluted disaccharides were analyzed using ChemStation software (Agilent Technologies, Santa Clara, CA). Results were analyzed by the SPSS 16.0 for Windows software package (SPSS Inc., Chicago, IL). Differences in relative HS disaccharide expression as measured by SAX-HPLC were analyzed by independent samples student's $t$-tests. $P$ values $<0.05$ were considered significant.

\section{Histology}

Pellets were fixed in $4 \%$ paraformaldehyde covered by Cytoblock (Shandon Cytoblock, Thermo Scientific, EttenLeur, NL) and embedded in paraffin. Subsequently, 3- $\mu \mathrm{m}$ sections were cut, the middle of the pellets was determined, and sections were mounted onto APES-coated slides. Cartilage formation was assessed by hematoxylin and eosin (HE) and toluidine blue staining. Metachromasia was measured with the multispectral imaging system (Nuance FX, Cambridge Research \& Instrumentation, Inc [CRi], Woburn, MA) on the microscope (Leica DM4000B). This system enabled us to spectral unmix different wavelengths (range, 420-720 nm) and thereby distinguish the purple and blue staining. Finally, we measured the optical density of the unmixed pictures (ImageJ, U.S. National Institutes of Health, Bethesda, MD,) and calculated the ratio purple/blue.

\section{Glycosaminoglycan (GAG) Analysis}

GAGs were isolated from pellets by incubation with 0.1 $\mathrm{mmol} / \mathrm{L}$ EDTA/PBS and $20 \mu \mathrm{g}$ proteinase K (Invitrogen, Breda, NL) at $56^{\circ} \mathrm{C}$ overnight. GAG amounts were then measured by using the Blyscan Sulfated GAG Assay (Biocolor, Carrickfergus, UK) and normalized against DNA content according to the manufacturer's protocol.

\section{Immunohistochemistry}

Used antibodies, antibody concentrations, antigen retrieval, positive controls, and other antibody specifications are described in Table 2. ${ }^{34}$ Negative controls (PBS instead of first antibody) were included for all immunohistochemical stainings. The sections were evaluated according to staining intensity ( 1 = weak; 2 = moderate; $3=$ strong $)$ and the percentage of positive cells ( $1=$ $0-24 \% ; 2=25-49 \% ; 3=50-74 \% ; 4=75-100 \%$ ) by two observers independently ${ }^{35}$ for the center (most differentiated cells) and the periphery (more flattened/spindle cells) of the pellets. Sum score was calculated. One-way analysis of variance with Bonferroni's multiple comparison test was used for statistical analysis. $P$ values $<0.05$ were considered significant.

\section{Quantitative Reverse Transcriptase PCR}

Total RNA was isolated from the pellets using TRIzol reagent (Invitrogen) according to the manufacturer's protocol. A polytron homogenizer was used to pulverize the pellets. CDNA was synthesized from $0.5 \mu \mathrm{g}$ total RNA per sample as described previously. ${ }^{25}$ Primers for EXT1, EXT2, IHh (QT01850177, Qiagen, Venlo, NL), 
Table 2. Antibodies Used for Immunohistochemistry

\begin{tabular}{|c|c|c|c|c|c|}
\hline Antigen & Manufacturer & Positive Control & Staining & $\begin{array}{c}\text { Antibody } \\
\text { Concentration }\end{array}$ & $\begin{array}{l}\text { Antigen } \\
\text { Retrieval }\end{array}$ \\
\hline Collagen II & NeoMarkers & Growth plate & ECM & $1: 100$ & $\begin{array}{l}\text { Proteinase } \mathrm{K}+ \\
\text { hyaluronidase }\end{array}$ \\
\hline Collagen $X$ & Quartett & Growth plate & ECM & $1: 100$ & $\begin{array}{l}\text { Proteinase } \mathrm{K}+ \\
\text { hyaluronidase }\end{array}$ \\
\hline sox9 & Atlas & Testis & Nucleus & $1: 100$ & Citrate \\
\hline $\begin{array}{l}\text { HS chains } \\
(10 E 4)\end{array}$ & US Biological & Skin & Membrane; ECM & $1: 400$ & - \\
\hline $\begin{array}{c}\text { Syndecan2 } \\
(10 \mathrm{H} 4)\end{array}$ & David, G. ${ }^{34}$ & Growth plate & Membrane; ECM & $1: 50$ & - \\
\hline Syndecan3 & $\begin{array}{l}\text { Proteintech. } \\
\text { Group Inc. }\end{array}$ & Colorectal carcinoma & Cytoplasm & $1: 200$ & Citrate; NGS \\
\hline Syndecan4 & Atlas & Placenta & Cytoplasm & $1: 1000$ & Citrate \\
\hline Perlecan & Atlas & Placenta & Cytoplasm & $1: 1200$ & Citrate; NGS \\
\hline CD44v3 & Novocastra & Tonsil & $\begin{array}{l}\text { Membrane; } \\
\text { cytoplasm }\end{array}$ & $1: 200$ & Citrate \\
\hline $\begin{array}{c}\text { Phosphosmad } \\
1,5,8\end{array}$ & Cell Signaling & Colon & Nucleus & $1: 100$ & Citrate; elk milk \\
\hline Phosphosmad 2 & Cell Signaling & Kidney & Nucleus & $1: 125$ & Citrate; NGS \\
\hline Beta-catenin & $\begin{array}{l}\text { Transduction } \\
\text { Biosciences }\end{array}$ & Skin & Cytoplasm & $1: 2000 ;, 1: 1600$ & Citrate \\
\hline PAl1 & $\begin{array}{l}\text { American } \\
\text { Diagnostics }\end{array}$ & Cervical carcinoma & Cytoplasm & $1: 200$ & - \\
\hline $\mathrm{Bcl} 2$ & Dako & Tonsil & Cytoplasm & $1: 1000$ & Citrate \\
\hline PTHLH & Oncogene & Skin & Cytoplasm & $1: 200$ & $\begin{array}{c}\text { Trypsin } 30 \\
\text { minutes }\end{array}$ \\
\hline PTHR1 & Upstate & Skin & Cytoplasm & $1: 400$ & Citrate \\
\hline NDST1 & Abcam & Ileum & Cytoplasm & $1: 800$ & Tris-EDTA \\
\hline
\end{tabular}

ECM indicates extracellular matrix; NGS, normal goat serum.

PTCH, SMO, GLI1, GLI2, and GLI3 were described previously. ${ }^{23,25}$ Three house keeping genes, G-coupled protein receptor 108 (GPR108), cleavage and polyadenylation specific factor 6 (CPSF6) and TATA Box-binding protein (TBP), were selected to normalize the expression levels. ${ }^{25}$

\section{Results}

\section{Genetic Analysis of MO Patients and Solitary and Hereditary OCs}

Of eight patients clinically documented to have MO, five contained a germline mutation in EXT1 and one patient demonstrated an EXT2 mutation in lymphocyte DNA (Table 1). Of the two patients negative at DNA sequencing and MLPA analysis, one demonstrated a germline intronic deletion and gain in the EXT1 region at DNA tiling array, while the other patient was normal at DNA tiling array. To search for a second hit, we examined DNA derived from the tumor tissue using sequencing analysis, and homozygosity for the mutated allele was found in three of five hereditary cases analyzed (Figure 1, A and B). In solitary OCs, two of three cases showed homozygous deletion of EXT1 at DNA tiling array (Figure 1, C and D). EXT1 and EXT2 mRNA expression was diminished in the majority of the OCs compared to the growth plate mRNA expression (Table 1).

\section{Chrondrogenesis of Normal, SO, and MO MSCs}

We used the 3D-pellet model of MSCs to study chondrogenesis and to mimic the cartilage cap as closely as possible. This model enables the comparison of signaling in wild-type versus EXT heterozygous cells differentiated toward the same cell type. To assess that we indeed cultured MSCs, we performed flow cytometric analysis which confirmed the expression of the MSC markers CD73, CD90, and CD105 and the absence of hematopoietic markers on adherent cells expanded from bone marrow. Moreover, the MSCs had the capacity to undergo adipogenesis and osteogenesis (data not shown). To confirm the neoplastic origin of cells cultured from the cartilaginous cap we assessed the presence of genetic aberrations that were found in the corresponding frozen tissue. Intriguingly, although macroscopically strictly cartilaginous tissue dissected from the cap was used for culturing, the pellets from the cultured cartilage cap cells appeared to be derived from normal cells instead of tumor cells as the $8 \mathrm{q}$ alterations that were shown in DNA isolated from frozen tumor tissue using DNA tiling array were absent in the cultured cells (data not shown). These were not used for further analysis. Therefore we used fresh frozen and paraffin embedded tissue from the cartilage cap for comparison with the pellets.

All MSCs were able to undergo chondrogenesis in vitro, although there was a large inter-donor variability with regard to pellet size. Deposition of cartilaginous 
A

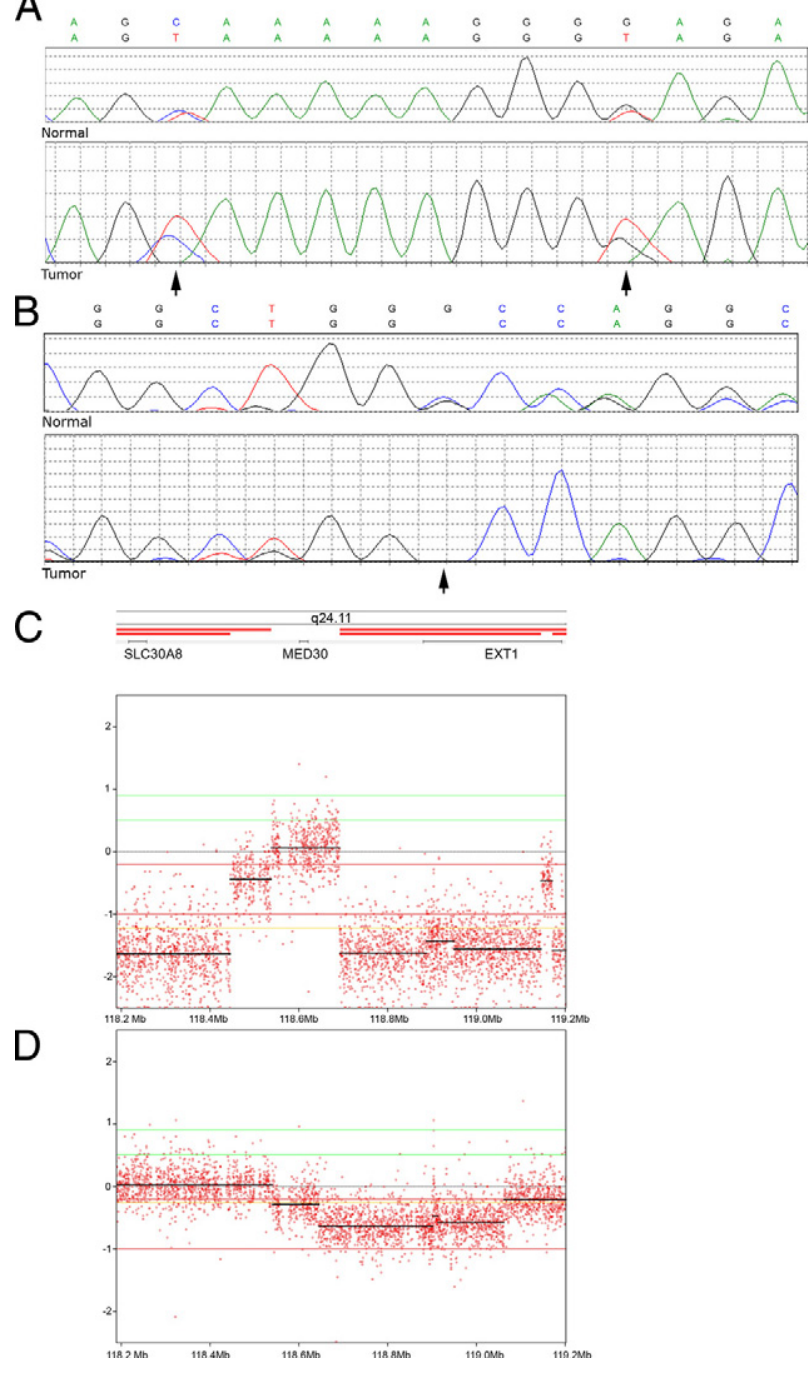

Figure 1. Second hit in hereditary and solitary osteochondromas. A: L2227 heterozygous germline mutation in EXT1, exon 1 c.364C $>$ T, p.Gln122X, and c. $373 \mathrm{G}>\mathrm{T}$, p.Glu125X (upper panel) with predominance of the sequence of the mutated allele in the tumor DNA (lower panel, arrows), suggesting loss of the wild-type allele. B: L2254 heterozygous mutation in EXT2, exon 6 c.980delG, p.Gly327AlafsX5 in germline (upper panel) with homozygosity in the tumor DNA (lower panel, arrow). C and D: DNA tiling results of the solitary tumors, representing the $8 \mathrm{q} 24.11$ region and showing a homozygous and partly hemizygous loss of the EXT1 allele in L2084 (C) and L2370 (D). Additionally, L2084 also has a homozygous loss of a region near EXT1. The values are not as low as expected due to contamination with normal cells.

matrix as determined by metachromasia at toluidine blue staining was shown at 2 weeks in 5/12, at 4 weeks in $11 / 12$, and at 6 weeks in $11 / 12$ pellets (Figure 2, A-C) quantified using the multispectral imaging system (Supplemental Table 2 and Supplemental Figure S1 available at $h$ ttp://ajp.amjpathol.org). There were no differences between normal $(\mathrm{N})$, SO $\left(E X T^{w t / w t}\right)$, and $\mathrm{MO}\left(E X T^{w t-}\right)$ MSCs. The results were confirmed on protein level using immunohistochemistry for collagen II (Figure 2, D and E). Collagen $X$ expression, indicative of hypertrophic differentiation, was mainly seen at 6 weeks (Figure 2, G and $H)$. Collagen II and X were also expressed in the OCs (Figure 2, F and I). Nuclear SOX9 is highly expressed in all pellets (EXTwt/wt and EXTwt/-) and OCs (data not shown).

\section{EXT and HS Analysis in EXT ${ }^{\mathrm{wt} / \mathrm{wt}}$ versus EXT ${ }^{\mathrm{wt} /-}$ MSCs, Pellets, and OCs}

We compared the 3D pellets from MSCs of normal donors with those of patients carrying a germline EXT1 mutation. EXT1 and EXT2 mRNA was expressed in all pellets although the levels were variable and lower as compared to growth plate expression (data not shown). Because the EXT1/EXT2 complex is involved in HS biosynthesis, we analyzed the GAGs. An increase in sulfated GAGs, including HS, was found using the Blyscan method in the EXTwt/wt and EXTwt/- pellets with increasing culture time. No significant difference of GAG production was found between EXTwt/wt and EXTwt/- pellets (data not shown). Because EXT1 and EXT2 are involved in HS chain length elongation, we determined the HS chain lengths of the EXT1 $1^{w t / w t}$ and EXT1 $1^{w t-}$ MSCs in monolayer culture (Figure $3, A$ and $B$ ). The HS chains were similar (between $80-120 \mathrm{kDa}$ ) and normal in length. HS disaccharide expression also revealed no significant differences between EXT1 $1^{\text {wt } / w t}$ and EXT1 ${ }^{w t /-}$ MSCs (Figure 3, C and D).

Using immunohistochemistry we could additionally compare the EXTwt/wt and EXTwt/- pellets with tumor tissue, in which EXT, at least in solitary $\mathrm{OCs},{ }^{8}$ is presumed to be homozygously inactivated $\left(E X T^{-1-}\right)$. Immunohistochemistry for HS chains (10E4) demonstrated membranous/cytoplasmatic expression of variable intensity in all pellets (Figure 2J). Interestingly, of the cartilaginous caps only 1 of 10 OCs was totally negative for HS expression, whereas 3 of 3 solitary and 6 of 7 hereditary OCs exhibited scattered tumor cells with cytoplasmatic and/or nuclear HS chain expression (Table 1; Figure 2, $\mathrm{K}$ and $\mathrm{L}$ ). The percentage of cells positive for 10E4 protein expression was not correlated with age or with detection of loss of heterozygosity, although one should take into account that the analyses were performed on different parts of the tumor; the staining on paraffin tissue and the DNA isolated from frozen tissue. The antibody 10E4 was shown to be specific for HS chains, because after heparitinase treatment $(10 \mathrm{mU} / \mathrm{ml})$ no HS could be detected (data not shown).

$\mathrm{N}$-deacetylase/n-sulfotransferase 1 (NDST1), an enzyme which is involved in the first step of HS chain modification, was abundantly expressed in the cytoplasm of the EXTwt/wt and EXTwt/- pellets and the OCs (Table 3). In addition the OCs showed nuclear (Figure 4D) and pericellular ECM NDST1 staining. There was focal NDST1 staining in ECM of the EXT ${ }^{w t / w t}$ and EXTwt/- pellets (Figure $4 \mathrm{~A})$.

\section{HSPG Analysis in EXTwt/wt versus EXTwt/- Pellets and OCs}

Expression of protein cores of HSPGs was studied using immunohistochemistry in pellets and tumor tissue. All HSPGs studied, including syndecans (SDC2-4), perlecan, and CD44v3 (HS bearing variable exon 3 of CD44), were expressed in the cytoplasm of the EXTwt/wt and EXTwt/- pellets and the OCs (Table 3; Figure 4, B, C, and E-J). The cytoplasmatic CD44v3 expression was signifi- 

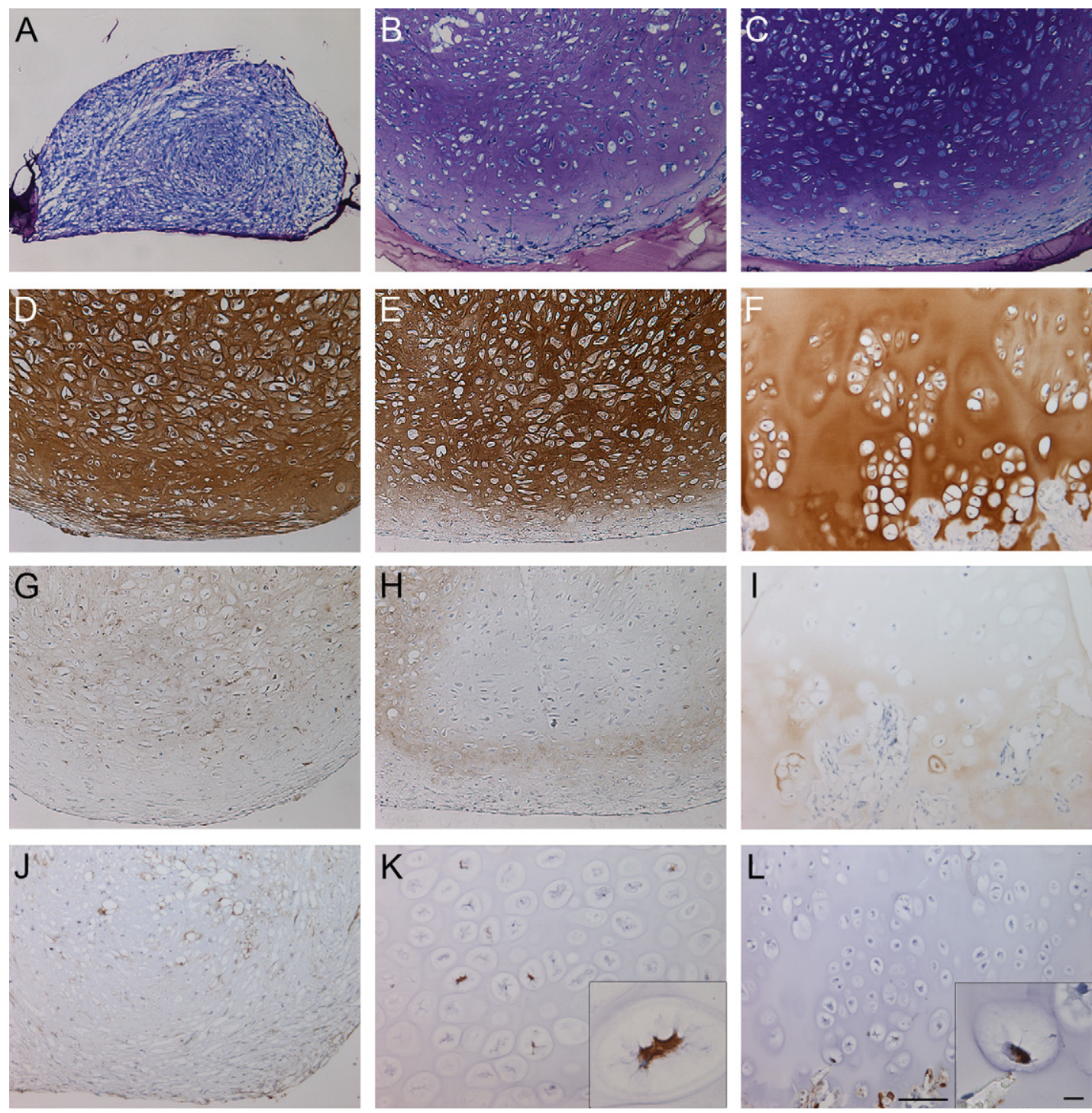

Figure 2. In vitro chrondrogenesis of normal, SO, and MO MSCs. Toluidine blue staining, EXT $T^{w t-}$ pellet after 2 , 4 , and 6 weeks of culture (A-C). Collagen II and collagen X expression, in EXT ${ }^{\text {wt } / w t}$ pellet, 6 weeks $(\mathbf{D}$ and $\mathbf{G}) ; E X T^{\text {wt }-}$ pellet, 6 weeks $(\mathbf{E}$ and $\mathbf{H}) ;$ OC L2370 $(\mathbf{F}$ and $\mathbf{I})$, respectively. Membranous/cytoplasmatic HS chain expression in wild-type pellet (J). Cytoplasmatic HS chain expression in the OCs (K and $\mathbf{L}$ ). HS-negative cells are intermingled with either more (L2467, no detection of second hit) (K) or fewer 10E4-positive cells (L2370, homozygous loss of EXT1 detected) (L). Scale bars: $100 \mu \mathrm{m}(\mathbf{A}-\mathbf{L}) ; 10 \mu \mathrm{m}(\mathbf{i n s e t} \mathbf{K}$ and $\mathbf{L})$.

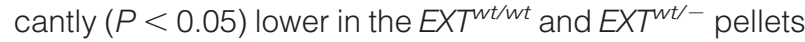
compared to the OCs (Figure 4, G and J). Focal nuclear SDC2, SDC3 and CD44v3 (dot-like) staining was ob-

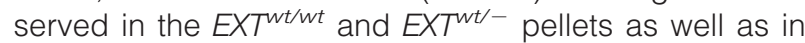
OCs. The ECM of the EXTwt/wt and EXT ${ }^{w t /}$ pellets focally expressed SDC2 and SDC4, whereas the ECM of the OCs had a pericellular ECM expression of SDC3 and perlecan near the ossification zone.

\section{Downstream Signaling Pathways Dependent on HS}

\section{IHh Signaling}

IHh signaling was active in the pellets and OCs, because the members of the pathway $(I H h, P T C H, S M O$, GLI1, GLI2, GLI3) were expressed at mRNA level (data not shown). PTHLH signaling, which is downstream of
IHh in normal growth plate, was active in the pellets and OCs because PTHLH and the PTH-receptor (PTHR1) were detected using immunohistochemistry. Bcl2, which is activated by the PTHR1, was not expressed in the EXT ${ }^{w / w t}$ and EXT ${ }^{w t /-}$ pellets nor in the OCs (Table 3).

\section{BMP and TGF- $\beta$ Signaling}

Phosphosmad 1,5,8 and phosphosmad 2 staining was positive in the nucleus of cells in the EXTwt/wt and EXTwt/pellets and OCs (Table 3). The EXTwt/wt and EXTwt/pellets exhibited a significant $(P<0.05)$ higher mean sum score of phosphosmad 1,5,8 expression in the nucleus compared to the OCs (Figure 4, $\mathrm{H}$ and $\mathrm{K}$ ). Also, plasminogen activator inhibitor 1 (PAl1) was significantly higher expressed in the cytoplasm of the EXT ${ }^{w t} / w t$ and EXT ${ }^{w t /-}$ pellets compared to the OCs (Figure 4, I and L; Table 3). Focal nuclear PAl1 expression was found in the 
A

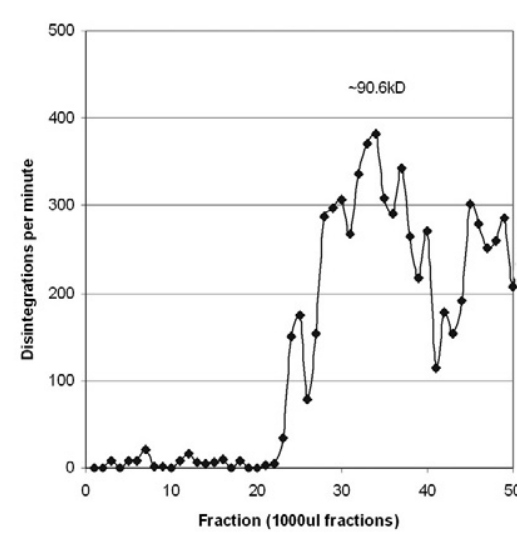

C

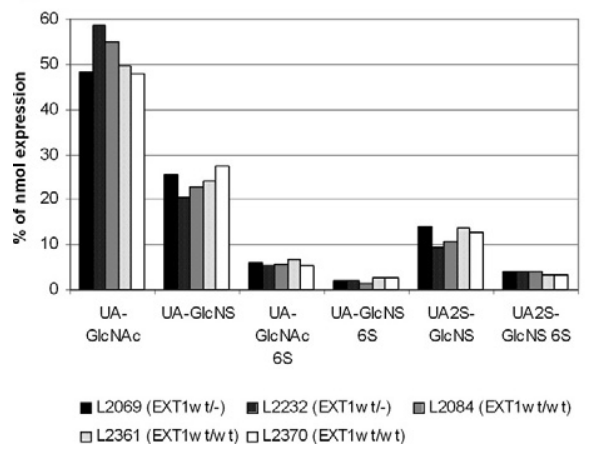

B

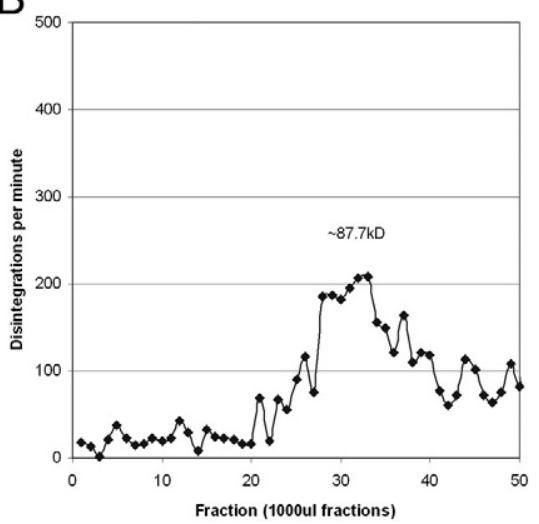

D

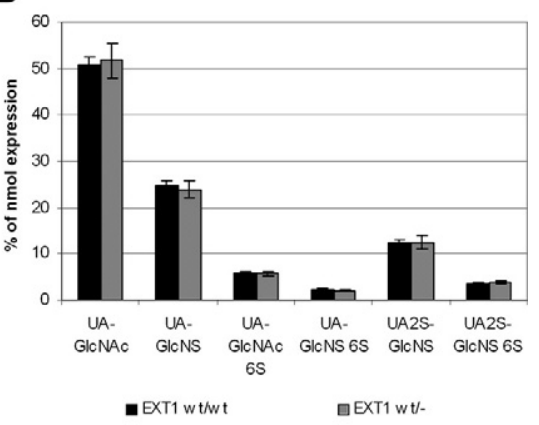

Figure 3. HS chain length and HS composition in EXT1 $1^{w t / w t}$ and EXT1 $1^{w t /-}$ MSCs. HS chain length was determined in EXT1 $1^{w t / w t}$ (L2370, $89,000 \mathrm{dpm}$ analyzed, size $\sim 90.6 \mathrm{kDa}$ ) (A) and EXT1 $^{\text {wt }}$ - (L2232, 51,600 dpm analyzed, size $\sim 87.7 \mathrm{kDa}$ ) (B) MSCs on a CL-6B Sepharose column. The average HS chain size of the MSCs was estimated from extrapolation of a CL-6B Sepharose standard curve to be $80-120 \mathrm{kDa}^{33}$ C: Relative expression of HS dissacharides per sample. D: Relative expression of HS disaccharides in $E X T 1^{w t / w t}(n=3)$ and EXT1 $1^{w t-}$ MSCs $(n=2)$ as analyzed by SAX-HPLC. No significant differences were observed between $E X T 1^{w t / w t}$ and EXT1 $1^{\text {wt }}-$ MSCs. Error bars indicate the SEM.
EXTwt/wt and EXTwt/- pellets and the OCs. Thus, BMPand TGF- $\beta$ signaling seem to be more active in the pellets as compared to the tumor samples.

\section{Wnt Signaling}

Cytoplasmatic and some nuclear $\beta$-catenin staining was observed in the EXT $T^{w t w t}$ and EXT $T^{w t /}$ pellets and OCs
(Table 3). The 2-week EXTwt/- pellets expressed a significant $(P<0.05)$ higher level of cytoplasmatic $\beta$-catenin mean sum score than the 6-week EXTwt- pellets (data not shown).

\section{Discussion}

In the present study we addressed the long-debated question of whether OCs in MO patients develop via

Table 3. Results of Immunohistochemistry of EXT-Related Genes and HS-Dependent Pathways

\begin{tabular}{|c|c|c|c|c|c|c|c|c|}
\hline & \multirow[b]{3}{*}{$P<0.05$} & \multicolumn{7}{|c|}{ Localization } \\
\hline & & \multicolumn{3}{|c|}{ Pellets (EXTwt/wt; EXTwt/-) } & \multicolumn{4}{|c|}{$\mathrm{OC}\left(E X T^{-/-}\right)$} \\
\hline & & Cytoplasm & Nucleus & ECM & Cytoplasm & Nucleus & ECM & $\bar{N}$ \\
\hline NDST1 & No & ++ & - & \pm & ++ & ++ & $t^{*}$ & $9 / 9$ \\
\hline SDC2 & No & ++ & $\pm(6$ weeks $)$ & \pm & ++ & \pm & - & $9 / 9$ \\
\hline SDC3 & No & + & \pm & - & + & \pm & $t^{* \neq}$ & $9 / 9$ \\
\hline SDC4 & No & ++ & - & $\pm(2$ weeks $)$ & ++ & - & - & $8 / 8$ \\
\hline Perlecan & No & + & - & $-(<+0)$ & + & - & $\pm^{\star \neq}$ & $6 / 6$ \\
\hline CD44v3 & Yes & \pm & $\pm \S$ & $\pm^{\dagger}$ & + & $\pm \S$ & $\overline{ \pm}^{*}$ & $8 / 8$ \\
\hline Phosphosmad 1,5,8 & Yes & - & $\overline{+}+$ & - & - & $\overline{+}$ & - & $7 / 8$ \\
\hline Phosphosmad 2 & No & - & + & - & - & + & - & $7 / 7$ \\
\hline PAl1 & Yes & ++ & \pm & - & + & \pm & - & $9 / 9$ \\
\hline$\beta$-Catenin & No & + & \pm & - & + & $\overline{+}$ & - & $8 / 8$ \\
\hline PTHLH & No & + & - & - & ++ & - & - & $9 / 9$ \\
\hline PTHR1 & No & + & - & - & + & - & - & $8 / 8$ \\
\hline $\mathrm{Bcl} 2$ & No & - & - & - & - & - & - & $0 / 9$ \\
\hline
\end{tabular}

OC indicates osteochondroma; ECM, extracellular matrix; wk, weeks of culturing; $\mathrm{N}$, number of positive OCs.

$++=$ strongly positive (mean sum score $>5$ ); $+=$ positive (mean sum score $3-5) ; \pm=$ focal $(2) ;-=$ negative.

*Pericellular.

${ }^{\dagger}$ Membranous.

¥Ossification zone; §ot-like.

Statistical analysis: one-way ANOVA, Bonferroni's Multiple comparison test in which all groups were compared; Significant differences $(P<0.05)$ were present between the pellets and OCs. 

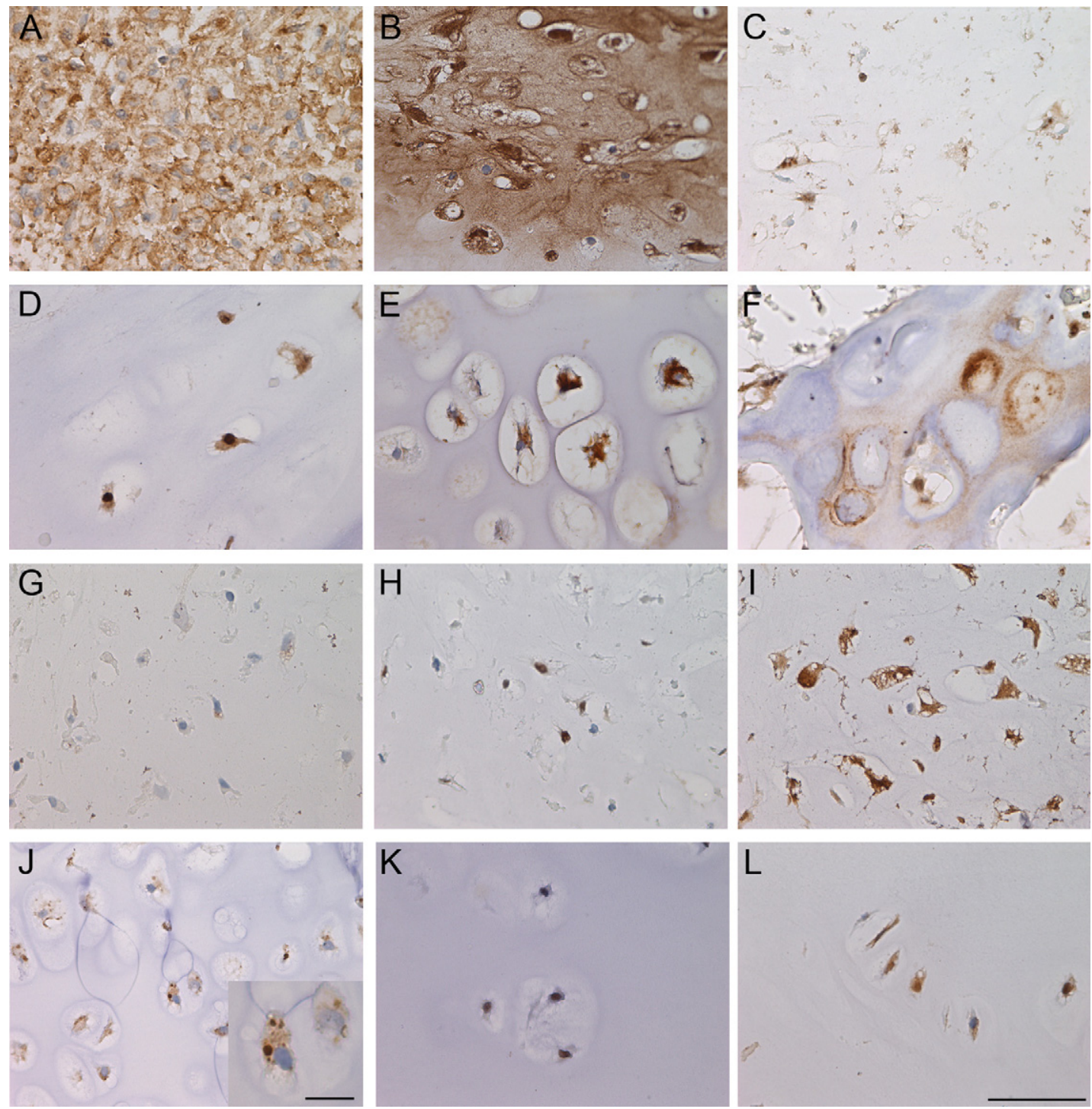

Figure 4. Protein expression of EXT-related genes and HS-dependent pathways in pellets and OCs. Cytoplasmatic NDST1 protein expression in pellets (A) versus nuclear and cytoplasmatic staining in the OCs (L2804; D). SDC2 protein expression is present in the ECM of the pellets (B), while absent in the OCs (L2370; E). SDC3 protein expression is absent in the ECM of the pellets $(\mathbf{C})$ and present in the OCs (L2467; F). Cytoplasmatic CD44v3 protein is predominantly expressed in OCs (dot-like; L2370; $\mathbf{J}$ ) and weakly in pellets (G). Both BMP (nuclear phosphosmad1) and TGF- $\beta$ (cytoplasmatic PAI1) signaling is active in the pellets (H and I) and OCs (L2370) (K and $\mathbf{L})$, respectively. Scale bars: $50 \mu \mathrm{m}(\mathbf{A}-\mathbf{L}) ; 10 \mu \mathrm{m}$ (inset $\mathbf{J})$

haploinsufficiency (gene dosage model, ie, the loss of one EXT allele) $)^{13,14,36}$ or via the classical two-hit model for tumor suppressor genes. ${ }^{5,7}$ Loss of heterozygosity of EXT1 and/or EXT2 was shown in solitary OCs ${ }^{6-8}$ as well as in a proportion of hereditary OCs, ${ }^{7}$ supporting the two-hit model. However, in a considerable number of hereditary OCs loss of the remaining wild-type allele could not be found, giving rise to the question whether OCs in MO patients could arise through haploinsufficiency. We therefore compared EXT, HS, HSPG, and the HS-dependent signaling pathways between cells containing a heterozygous mutation in EXT1 or EXT2 (EXTwt/- MSCs of MO patients) and wild-type cells (EXT ${ }^{w t / w t}$ MSCs of healthy donors and SO patients). Results were compared to tumor tissue, in which EXT, at least in solitary OCs, ${ }^{8}$ is presumed to be homozygously affected $\left(E X T^{-1-}\right)$.
In the present series the predominance of the mutated allele at DNA sequence analysis of the tumor tissue suggested loss of the remaining wild-type allele in three of five patients carrying a germline EXT mutation. Two of three solitary OCs demonstrated homozygous deletion of EXT1. EXT mRNA expression in these cases was diminished compared to growth plate mRNA expression and comparable to the earlier reported expression levels in OCs. ${ }^{23}$ The fact that a second hit could be demonstrated in $63 \%$ of cases (5/8; both solitary and hereditary) is similar to published data. ${ }^{6-8}$

We successfully induced chondrogenesis both in EXT ${ }^{w t}{ }^{\text {wt }}$ and EXT ${ }^{w t-}$ MSCs, and cartilaginous differentiation was confirmed by metachromasia with toluidine blue and by the expression of collagen II, SOX9 and collagen X (hypertrophic differentiation). We did not observe a difference in chondrogenesis between EXT ${ }^{\text {wt }}{ }^{w t}$ and EXT ${ }^{\text {wt }}$ - 
MSCs. Thus, our data indicate that inactivation of one EXT allele does not impair cartilage formation.

EXT1 and EXT2 are responsible for HS chain length elongation. Here we show that the HS chain length and HS structure are identical in EXT't/wt and EXT ${ }^{w t /-}$ MSCs and that the HS chain length of the MSCs is within the normal range. ${ }^{37}$ EXT mutations are reported to affect HS chain length. ${ }^{38}$ EXT1 or EXT2 down-regulation will lead to shortened HS chains, whereas EXT1 (and EXT2) overexpression will lead to elongated HS chains. ${ }^{39}$ We did not observe a difference in EXT expression nor in HS staining between EXTwt/wt and EXT ${ }^{w t-}$ pellets. Our results in human differ from those in mice, of which heterozygous Ext1-deficient embryonic stem cells show a reduction in transferase activity and in HS level compared to wild-type cells. ${ }^{40}$ The fact that in human HS chain length as well as its structure is normal in MSCs carrying a heterozygous EXT mutation supports the notion that loss of a single EXT allele does not affect HS biosynthesis and therefore strongly argues against haploinsufficiency. However, our results were found in MSCs in monolayer culture, and because HSPG composition is tissue-specific ${ }^{41}$ one cannot completely rule out that chain lengths are different when cells are differentiated toward cartilage. Moreover, because culturing of $E X T^{-1-}$ cartilaginous cap cells failed we could not confirm and compare to a presumed reduced chain length in EXT ${ }^{-1-}$ cells.

The expression of HS, different HSPGs, as well as downstream signaling molecules was not significantly different between normal MSCs and MSCs carrying a heterozygous EXT mutation. Interestingly, the majority of OCs exhibited focal cytoplasmatic and/or nuclear HS expression. This suggests that the cartilage cap still contains a number of nonmutated cartilaginous cells with a normal HS chain length. The localization of the HSPG protein cores differed between the pellets and OCs. The CD44v3 expression is significantly lower in the pellets as compared to the OCs. This is in line with previous data of CD44v3 expression to be significantly lower in growth plate compared to the OCs. ${ }^{23} \mathrm{CD} 44 \mathrm{v} 3$ expression therefore seems to be tumor-specific. Of the HS dependent signaling pathways, activity of both BMP (phosphosmad $1,5,8$ ) and TGF- $\beta$ signaling (PAl1) was shown to be significantly higher in the pellets compared to the OCs. It is likely that the activity of those pathways in the pellets is (partly) caused by the supplements, TGF- $\beta$ and BMP-6, which were added in the medium during in vitro chondrogenesis.

Thus, our data strongly argue against haploinsufficiency of EXT1 or EXT2 as an explanation for OC formation because HS chain length and structure, in vitro chondrogenesis and the expression of EXT, HS and EXT downstream molecules were identical in EXT ${ }^{w t /}$ and EXTwtiwt cells. However, the second hit could not be detected in 3/8 OCs in our series despite a low EXT expression level in those OCs. Alternative mechanisms may exist causing (near) complete inactivation of EXT. Epigenetic gene silencing by methylation in the EXT1 and EXT2 promoter region was however shown to be absent. ${ }^{23,42,43}$ Other alterations in or nearby the promoter region or the involvement of microRNAs cannot be excluded.
Our results, however, provide an alternative explanation for the fact that the second hit is not always detectable in OC. We observed some remaining HS expression in the cartilage cap. Furthermore, we repeatedly cultured EXT $T^{w t /-}$ or EXT ${ }^{w t}$ twt cells instead of EXT ${ }^{-1-}$ cells from the carefully dissected cartilaginous cap. Moreover, EXT expression at mRNA level is decreased in OC, but there is always some expression remaining. ${ }^{23}$ These data may suggest that the cartilage cap is heterogeneous in composition, comprising not only EXT ${ }^{-1-}$ tumor cells but also normal cells in between the tumor cells (mosaicism). The need for a second hit was recently confirmed in a conditional Ext1 mouse model. While Ext1 $1^{+/-}$and Ext2 ${ }^{+/-}$ mice do not show OCs of the long bones, ${ }^{36,40,44}$ complete inactivation of EXT1 in chondrocytes results in a phenotype strongly resembling human MO. ${ }^{45}$ Interestingly, the cartilage caps of the mouse OCs also demonstrate a mixture of mutated and normal cells indicating mosaicism. ${ }^{45}$ This is in accordance with the zebrafish model of Clement and colleagues, ${ }^{46}$ who suggested a loss of heterozygosity model for OC formation in which loss of polarity leads to the cartilage cap of an OC which major component consists of EXT $T^{-1-}$ chondrocytes and its minor component of hypertrophic EXTwt- chondrocytes. The HS staining of the human OCs suggests however that the normal cells are not restricted to the hypertrophic zone (as in the zebrafish model) ${ }^{46}$ or to small single clones (as in the mouse model) ${ }^{45}$ but are intermingled with the HS negative cells. The detection of loss of the remaining wild-type allele in OC using DNA based techniques will depend on the ratio of normal versus mutant cells.

In conclusion, we could demonstrate a second hit in the EXT genes in five of eight OCs, including both solitary and hereditary OCs. MSCs carrying a heterozygous EXT mutation are identical to wild-type MSCs with regard to HS chain length and structure, in vitro chondrogenesis, and the expression of EXT, HS, and their downstream molecules. Therefore, our results refute the haploinsufficiency theory and strongly support the two-hit model for OC formation. The heterogeneous composition of the cartilaginous cap, containing both HS-positive and HSnegative cells, suggests that the detection of the second hit in OC depends on the ratio of normal versus mutated cells in the cartilaginous cap.

\section{Acknowledgments}

We thank Armin W. Walter (Onze Lieve Vrouwe Gasthuis, Amsterdam, The Netherlands), and Antonie H. M. Taminiau for kindly providing the patient material; Sahila Balkassmi for the EXT mutation analysis; Daniëlle de Jong for expert assistance with the DNA tiling array; Helene Roelofs for providing the healthy donor MSCs; Jarom Heijmans for the IHh primers; Razvan L. Miclea, Salvatore Romeo, and Malgorzata Wiweger for their expertise; Brendy van den Akker, Maayke van Ruler, Hans J. Baelde, Inge Briaire-de Bruijn, Ronald Duim, and Marcel Winter for their practical assistance; and Frans Prins for his professional help with the spectral imaging. 


\section{References}

1. Khurana J, Abdul-Karim F, Bovée JVMG: Osteochondroma. World Health Organization classification of tumours. Pathology and genetics of tumours of soft tissue and bone. Edited by CDM Fletcher, KK Unni, and F Mertens. Lyon, France, IARC Press, 2002, pp. 234-236

2. Bovée JVMG Hogendoorn PCW: Congenital and inherited syndromes associated with bone and soft tissue tumours: Multiple osteochondromas. World Health Organisation classification of tumours. Pathology and genetics of tumours of soft tissue and bone. Edited by CDM Fletcher, KK Unni, and F Mertens. Lyon, France, IARC Press, 2002, pp. 360-362

3. Legeai-Mallet L, Munnich A, Maroteaux P, Le Merrer M: Incomplete penetrance and expressivity skewing in hereditary multiple exostoses. Clin Genet 1997, 52:12-16

4. Bovée JVMG: Multiple osteochondromas. Orphanet J Rare Dis 2008 , $3: 3$

5. Knudson AG Jr: Mutation and cancer: statistical study of retinoblastoma. Proc Natl Acad Sci USA 1971, 68:820-823

6. Bernard MA, Hall CE, Hogue DA, Cole WG, Scott A, Snuggs MB, Clines GA, Ludecke HJ, Lovett M, Van Winkle WB, Hecht JT: Diminished levels of the putative tumor suppressor proteins EXT1 and EXT2 in exostosis chondrocytes. Cell Motil Cytoskeleton 2001, 48:149-162

7. Bovée JVMG, Cleton-Jansen AM, Wuyts W, Caethoven G, Taminiau AHM, Bakker E, Van Hul W, Cornelisse CJ, Hogendoorn PCW: EXTmutation analysis and loss of heterozygosity in sporadic and hereditary osteochondromas and secondary chondrosarcomas. Am J Hum Genet 1999, 65:689-698

8. Hameetman L, Szuhai K, Yavas A, Knijnenburg J, van Duin M, Van Dekken H, Taminiau AHM, Cleton-Jansen AM, Bovée JVMG, Hogendoorn PCW: The role of EXT1 in nonhereditary osteochondroma: identification of homozygous deletions. J Natl Cancer Inst 2007, 99:396-406

9. Hallor KH, Staaf J, Bovée JVMG, Hogendoorn PCW, Cleton-Jansen AM, Knuutila S, Savola S, Niini T, Brosjo O, Bauer HCF, Vult von Steyern F, Jonsson K, Skorpil M, Mandahl N, Mertens F: Genomic profiling of chondrosarcoma: chromosomal patterns in central and peripheral tumors. Clin Cancer Res 2009, 15:2685-2694

10. Hecht JT, Hogue D, Strong LC, Hansen MF, Blanton SH, Wagner M: Hereditary multiple exostosis and chondrosarcoma: linkage to chromosome 11 and loss of heterozygosity for EXT-linked markers on chromosomes 11 and 8. Am J Hum Genet 1995, 56:1125-1131

11. Raskind WH, Conrad EU, Chansky H, Matsushita M: Loss of heterozygosity in chondrosarcomas for markers linked to hereditary multiple exostoses loci on chromosomes 8 and 11. Am J Hum Genet 1995, 56:1132-1139

12. Bernard MA, Hogue DA, Cole WG, Sanford T, Snuggs MB, MontufarSolis D, Duke PJ, Carson DD, Scott A, Van Winkle WB, Hecht JT: Cytoskeletal abnormalities in chondrocytes with EXT1 and EXT2 mutations. J Bone Miner Res 2000, 15:442-450

13. Hall CR, Cole WG, Haynes R, Hecht JT: Reevaluation of a genetic model for the development of exostosis in hereditary multiple exostosis. Am J Med Genet 2002, 112:1-5

14. Legeai-Mallet L, Rossi A, Benoist-Lasselin C, Piazza R, Mallet JF, Delezoide AL, Munnich A, Bonaventure J, Zylberberg L: EXT 1 gene mutation induces chondrocyte cytoskeletal abnormalities and defective collagen expression in the exostoses. J Bone Miner Res 2000, 15:1489-1500

15. Lind T, Tufaro F, McCormick C, Lindahl U, Lidholt K: The putative tumor suppressors EXT1 and EXT2 are glycosyltransferases required for the biosynthesis of heparan sulfate. J Biol Chem 1998 , 273:26265-26268

16. McCormick C, Leduc Y, Martindale D, Mattison K, Esford LE, Dyer AP, Tufaro F: The putative tumour suppressor EXT1 alters the expression of cell-surface heparan sulfate. Nat Genet 1998, 19:158-161

17. McCormick C, Duncan G, Goutsos KT, Tufaro F: The putative tumor suppressors EXT1 and EXT2 form a stable complex that accumulates in the golgi apparatus and catalyzes the synthesis of heparan sulfate. Proc Natl Acad Sci USA 2000, 97:668-673

18. Simmons AD, Musy MM, Lopes CS, Hwang L-Y, Yang Y-P, Lovett M: A direct interaction between EXT proteins and glycosyltransferases is defective in hereditary multiple exostoses. Hum Mol Genet 1999, 8:2155-2164

19. Bellaiche Y, The I, Perrimon N: Tout-velu is a drosophila homologue of the putative tumour suppressor EXT1 and is needed for Hh diffusion. Nature 1998, 394:85-88

20. Han C, Belenkaya TY, Khodoun M, Tauchi M, Lin X, Lin X: Distinct and collaborative roles of Drosophila EXT family proteins in morphogen signalling and gradient formation. Development 2004, 131:1563-1575

21. Takei Y, Ozawa Y, Sato M, Watanabe A, Tabata T: Three Drosophila EXT genes shape morphogen gradients through synthesis of heparan sulfate proteoglycans. Development 2004, 131:73-82

22. Toyoda H, Kinoshita-Toyoda A, Selleck SB: Structural analysis of glycosaminoglycans in drosophila and caenorhabditis elegans and demonstration that tout-velu, a drosophila gene related to EXT tumor suppressors, affects heparan sulfate in vivo. J Biol Chem 2000, 275:2269-2275

23. Hameetman L, David G, Yavas A, White SJ, Taminiau AHM, CletonJansen AM, Hogendoorn PCW, Bovée JVMG: Decreased EXT expression and intracellular accumulation of heparan sulphate proteoglycan in osteochondromas and peripheral chondrosarcomas. J Pathol 2007, 211:399-409

24. Benoist-Lasselin C, de Margerie E, Gibbs L, Cormier S, Silve C, Nicolas G, Lemerrer M, Mallet JF, Munnich A, Bonaventure J, Zylberberg L, Legeai-Mallet L: Defective chondrocyte proliferation and differentiation in osteochondromas of MHE patients. Bone 2006, 39:17-26

25. Hameetman L, Rozeman LB, Lombaerts M, Oosting J, Taminiau AHM, Cleton-Jansen AM, Bovée JVMG, Hogendoorn PCW: Peripheral chondrosarcoma progression is accompanied by decreased Indian Hedgehog $(\mathrm{IHH})$ signalling. J Pathol 2006, 209:501-511

26. Bovée JVMG, Van den Broek LJCM, Cleton-Jansen AM, Hogendoorn PCW: Up-regulation of PTHrP and Bcl-2 expression characterizes the progression of osteochondroma towards peripheral chondrosarcoma and is a late event in central chondrosarcoma. Lab Invest 2000, 80:1925-1933

27. Hameetman L, Kok P, Eilers PHC, Cleton-Jansen AM, Hogendoorn PCW, Bovée JVMG: The use of Bcl-2 and PTHLH immunohistochemistry in the diagnosis of peripheral chondrosarcoma in a clinicopathological setting. Virchows Arch 2005, 446:430-437

28. Vink GR, White SJ, Gabelic S, Hogendoorn PCW, Breuning $\mathrm{MH}$, Bakker E: Mutation screening of EXT1 and EXT2 by direct sequence analysis and MLPA in patients with multiple osteochondromas: splice site mutations and exonic deletions account for more than half of the mutations. Eur J Hum Genet 2004, 13:470-474

29. White SJ, Vink GR, Kriek M, Wuyts W, Schouten J, Bakker B, Breuning $\mathrm{MH}$, den Dunnen JT: Two-color multiplex ligation-dependent probe amplification: detecting genomic rearrangements in hereditary multiple exostoses. Hum Mutat 2004, 24:86-92

30. Schrage YM, Hameetman L, Szuhai K, Cleton-Jansen AM, Taminiau AHM, Hogendoorn PCW, Bovée JVMG: Aberrant heparan sulfate proteoglycan localization, despite normal exostosin, in central chondrosarcoma. Am J Pathol 2009, 174:979-988

31. Chen E, Stringer SE, Rusch MA, Selleck SB, Ekker SC: A unique role for 6-O sulfation modification in zebrafish vascular development. Dev Biol 2005, 284:364-376

32. Robinson CJ, Mulloy B, Gallagher JT, Stringer SE: VEGF165-binding sites within heparan sulfate encompass two highly sulfated domains and can be liberated by K5 lyase. J Biol Chem 2006, 281:1731-1740

33. Wasteson A: A method for the determination of the molecular weight and molecular-weight distribution of chondroitin sulphate. J Chromatogr 1971, 59:87-97

34. David G, Bai XM, Van der Schueren B, Marynen P, Cassiman JJ, Van den Berghe $\mathrm{H}$ : Spatial and temporal changes in the expression of fibroglycan (syndecan-2) during mouse embryonic development. Development 1993, 119:841-854

35. Bovée JVMG, Cleton-Jansen AM, Kuipers-Dijkshoorn N, Van den Broek LJCM, Taminiau AHM, Cornelisse CJ, Hogendoorn PCW: Loss of heterozygosity and DNA ploidy point to a diverging genetic mechanism in the origin of peripheral and central chondrosarcoma. Genes Chrom Cancer 1999, 26:237-246

36. Stickens D, Zak BM, Rougier N, Esko JD, Werb Z: Mice deficient in Ext2 lack heparan sulfate and develop exostoses. Development 2005, 132:5055-5068

37. Knox S, Merry C, Stringer S, Melrose J, Whitelock J: Not all perlecans are created equal: interactions with fibroblast growth factor (FGF) 2 and FGF receptors. J Biol Chem 2002, 277:14657-14665

38. Yamada S, Busse M, Ueno M, Kelly OG, Skarnes WC, Sugahara K, 
Kusche-Gullberg M: Embryonic fibroblasts with a gene trap mutation in EXT1 produce short heparan sulphate chains. J Biol Chem 2004, 279:32134-32141

39. Busse M, Feta A, Presto J, Wilen M, Gronning M, Kjellen L, KuscheGullberg M: Contribution of EXT1. EXT2, and EXTL3 to heparan sulfate chain elongation J Biol Chem 2007, 282:32802-32810

40. Lin X, Wei G, Shi Z, Dryer L, Esko JD, Wells DE, Matzuk MM: Disruption of gastrulation and heparan sulfate biosynthesis in EXT1- deficient mice. Dev Biol 2000, 224:299-311

41. Shi X, Zaia J: Organ-specific heparan sulfate structural phenotypes. J Biol Chem 2009, 284:11806-11814

42. Ropero S, Setien F, Espada J, Fraga MF, Herranz M, Asp J, Benassi MS, Franchi A, Patino A, Ward LS, Bovée J, Igudosa JC, Im W, Steller M: Epigenetic loss of the familial tumor-suppressor gene exostosin-1 (EXT1) disrupts heparan sulfate synthesis in cancer cells. Hum Mol Genet 2004, 13:2753-2765
43. Tsuchiya $T$, Osanai $T$, Ogose A, Tamura G, Chano $T$, Kaneko $Y$, Ishikawa A, Orui H, Wada T, Ikeda T, Namba M, Takigawa M, Kawashima H, Hotta T, Tsuchiya A, Ogino T, Motoyama T: Methylation status of EXT1 and EXT2 promoters and two mutations of EXT2 in chondrosarcoma. Cancer Genet Cytogenet 2005, 158:148-155

44. Hilton MJ, Gutierrez L, Martinez DA, Wells DE: EXT1 regulates chondrocyte proliferation and differentiation during endochondral bone development. Bone 2005, 36:379-386

45. Jones KB, Piombo V, Searby C, Kurriger G, Yang B, Grabellus F, Roughley PJ, Morcuende JA, Buckwalter JA, Capecchi MR, Vortkamp A, Sheffield VC: A mouse model of osteochondromagenesis from clonal inactivation of Ext1 in chondrocytes. Proc Natl Acad Sci USA 2010, 107:2054-2059

46. Clement A, Wiweger M, von der HS, Rusch MA, Selleck SB, Chien $\mathrm{CB}$, Roehl HH: Regulation of zebrafish skeletogenesis by ext2/dackel and papst1/pinscher. PLoS Genet 2008, 4:e1000136 